\title{
FLASH-BUTT WELDING OF THIN-WALLED PROFILES OF HEAT-HARDENED ALUMINIUM ALLOYS
}

\author{
P.N. CHVERTKO, L.A. SEMYONOV and K.V. GUSHCHIN \\ E.O. Paton Electric Welding Institute, NASU
}

11 Bozhenko Str., 03680, Kiev, Ukraine. E-mail: office@paton.kiev.ua

\begin{abstract}
Thin-walled profiles of high-strength aluminium alloys have found application in longitudinal load-carrying elements of flying vehicles and other critical structures. In industry, the serial profiles, heat-treated for maximum strength, are used, that excludes the feasibility of their welding by fusion arc methods. The problem of producing the welded joints of the above-mentioned load-carrying elements in solid phase is urgent. The present work is aimed at the study of formation of thin-walled profile joints of dissimilar (AK6 + D16) and similar (V95) heat-hardened aluminium alloys in the flash-butt continuous welding. Peculiarities of the resistance flash-butt welding with formation of joints during upsetting with extrusion were investigated and basic technology was developed, which is used for producing joints of aluminium alloy parts. This technology allows increasing greatly the quality of welded joints of this group of alloys, and also widening the range of thicknesses of metal, being joined by the flash-butt welding. Given are the main parameters of the flash-butt continuous welding modes. Strength properties of welded joints are not less than $90 \%$ of the base metal strength. 6 Ref., 8 Figures.
\end{abstract}

Key words: flash-butt welding, continuous flashing, upsetting, formation of joints, aluminium alloys

Alloys V95, D16 and AK6 are widely used in manufacture of critical elements and structures in aircraft and rocket construction. Thus, at the present time the riveted joints of alloys V95,
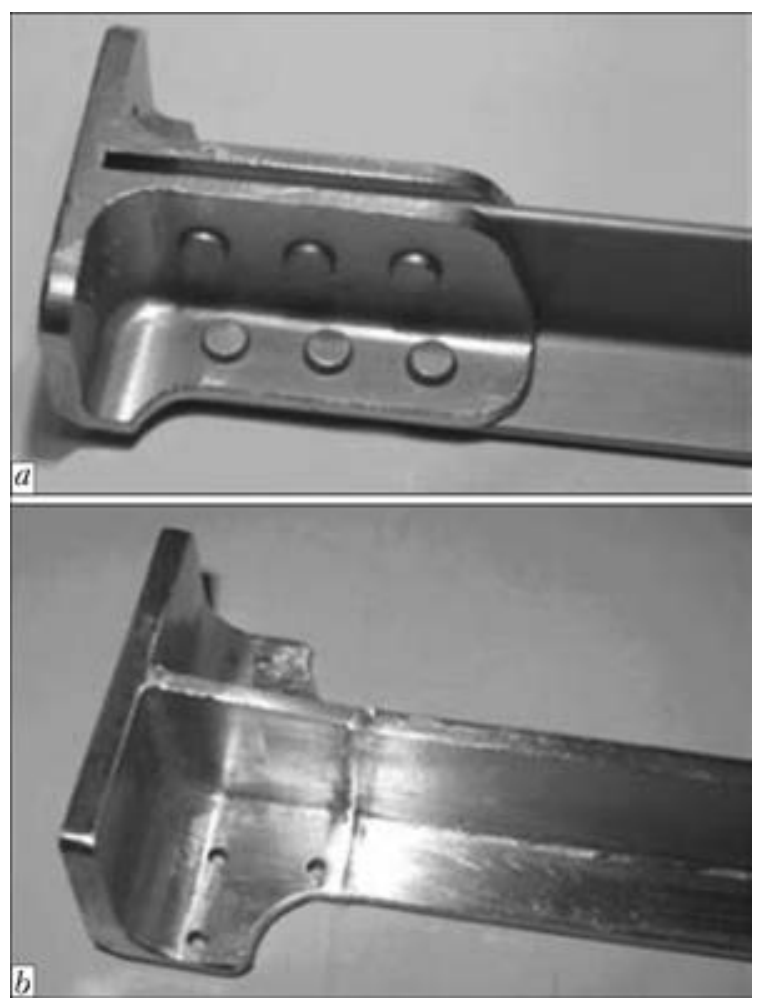

Figure 1. Joining of elements of fitting-stringer type of longitudinal load-carrying structure of flying vehicles by riveting $(a)$ and flash-butt welding $(b)$

๑ $\odot$ P.N. CHVERTKO, L.A. SEMYONOV and K.V. GUSHCHIN, 2014
AK6 + D16 are used for manufacture of a longitudinal load-carrying structure of casings of aerospace engineering equipment, because these alloys are referred to the hard-to-weld group. The important drawback of the riveted joint is the increase in mass of structure due to the appearance of auxiliary elements during riveting of elements being abutted (Figure 1, $a$ ). The riveting is a labor-consuming operation, connected with hard labor conditions. It is necessary to make a careful treatment of the hole surface for riveting to provide the reliable joining of the product. During long-term service the riveted joint is subjected to loosing, having an influence on the product service life.

Application of welding instead of riveting (Figure 1,b) is one of the effective methods of solution of the problem of improving the strength, quality of the joint and increasing the tactical-technical characteristics of flying vehicles, in particular, the decrease in structure mass and, accordingly, the increase in payload of the flying vehicles [1].

One of the main load-carrying elements of the flying vehicle structure is the stringer-fitting joints. Stringers are manufactured in majority of cases from T-section of high-strength heat-hardened alloys D16, V95, etc. Fittings are manufactured by milling from different semi-products (for example, forgings of alloy AK6 or plates of the same alloy as the stringer panels).

In this connection the assessment of weldability of thin-walled profiles of different sections 
of alloy V95-T1 and plates of alloy D16-T + AK6T1 was made during their welding.

Semi-products of alloy D16 and V95 have found a wide application in industry. These alloys are hardened by the heat treatment and, as a result, acquire the high mechanical properties and retain a sufficient technological ductility.

Among the high-strength alloys on aluminium base alloy $\mathrm{V} 95$, which is referred to $\mathrm{Al}-\mathrm{Zn}-\mathrm{Mg}-$ $\mathrm{Cu} \quad(5.0-7.0 \% \quad \mathrm{Zn}, \quad 1.8-2.8 \%$ Mg, $1.4-$ $2.0 \% \mathrm{Cu}$ ), found the largest application in rocket-space and aircraft structures. Zinc, magnesium and copper form solid solutions with aluminium and between themselves and different metallic compounds - phases $\mathrm{M}\left(\mathrm{MgZn}_{2}\right), \mathrm{S}$ $\left(\mathrm{Al}_{2} \mathrm{CuMg}\right), \mathrm{T}\left(\mathrm{Al}_{2} \mathrm{Mg}_{3} \mathrm{Zn}_{3}\right)$, playing a large role in alloy hardening at its heat treatment.

D16 is the alloy of, at least, six components: aluminium, copper, magnesium, manganese, iron and silicon, though the main alloying elements are copper and magnesium $(3.8-4.9 \% \mathrm{Cu}, 1.2-$ $1.8 \% \mathrm{Mg})$, therefore it refers to the alloys of $\mathrm{Al}-\mathrm{Cu}-\mathrm{Mg}$ system.

Alloy $\mathrm{AK} 6$ of $\mathrm{Mg}-\mathrm{Si}-\mathrm{Cu}$ alloying system is mainly used in the form of forgings, produced mainly from the pressed rods. Main alloying elements are magnesium, silicon and copper (0.6$1.0 \% \mathrm{Mg}, 0.9-1.0 \% \mathrm{Si}, 2.0 \% \mathrm{Cu})$. The alloy is widely used in industry (construction, transport machine building, aviation) for manufacture of stamped and forged parts of intricate shape, as well as for loaded parts of the type of frames, fittings, etc. Microstructure of alloy AK6 consists after heat treatment of grains of aluminium solid solution and inclusions of metallic compounds $\mathrm{CuAl}_{2}$ and $\mathrm{Mg}_{2} \mathrm{Si}$. Alloy AK6 is less sensitive to heating than alloys D16 and V95 [2, 3].

Thermomechanically strengthened alloys are very sensitive to heating. Degree of weakening depends on heating temperature and time of heating duration. During welding the highest mechanical properties can be obtained in that case when the duration of heating up to the temperatures above critical ones does not exceed the definite limits [4]. It is difficult to provide such temperature cycle in welding of aluminium alloys due to their heat conductivity. The intensive high-concentrated heat input to the heating zone is required.

One of the most challenging methods of producing the quality welded joints with high mechanical properties is the flash-butt welding (FBW) with a continuous flashing.

The present work is aimed at the study of peculiarities of formation of joints of thin-walled profiles of dissimilar (D16 + AK6) and similar

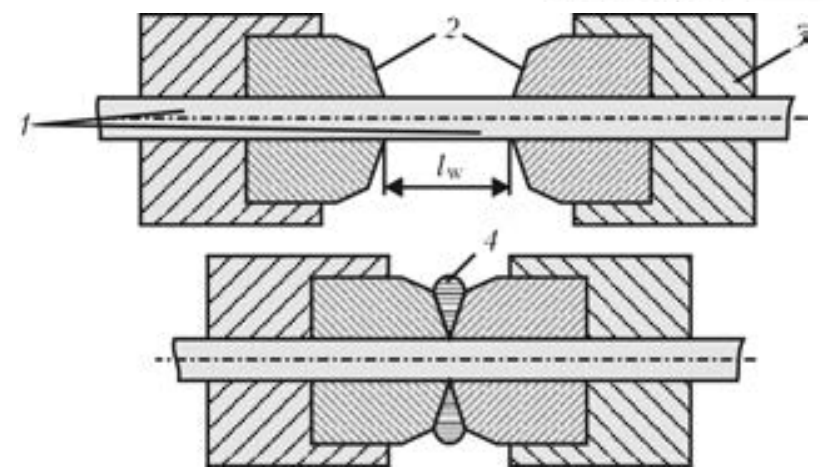

Figure 2. Scheme of FBW with formation of joint: 1 parts; 2 - forming devices; 3 - current connector; 4 extruded metal; $l_{\mathrm{w}}-$ tolerance for welding

(V95) heat-hardened aluminium alloys at the continuous FBW with extrusion.

The welding process is performed automatically, providing high stable quality of the joint. Design of welding equipment and technological rigs provide combining of assembly-welding works in a single cycle and high accuracy of the welded joint geometric sizes [5].

The obligatory condition of producing the quality welded joints of aluminium alloys is the formation of joint with metal extrusion during upsetting into gap between the forming devices. In this case, the degree of deformation is increased with knives approaching [6]. Scheme of FBW process with the joint formation is given in Figure 2. The forming devices are fulfilling two important functions: during upsetting they form the joint under conditions of volume-plastic deformation, and also fulfill the function of knives for the flash cutting. As a result the welded joint is formed, which does not need the next mechanical cleaning from the flash $\left(\mathrm{Fi}^{-}\right.$ gure 3 ).

Welding of alloys of different systems of alloying (D16-T and AK6-T1) was carried out on plates of 2.5-5.0 thickness and 25-35 mm width.

To make prototyping of the welded joint of elements of the fitting-stringer type, the investigations were carried out on T-section of alloy

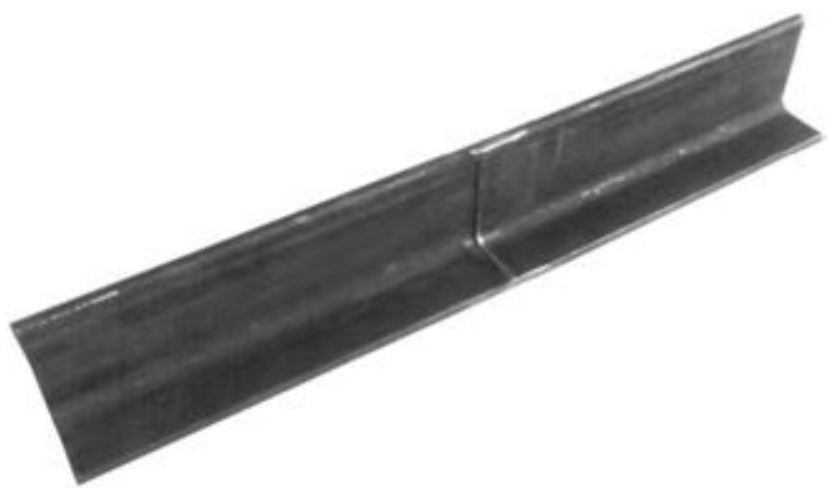

Figure 3. Welded joint of T-section profile of aluminium alloy V95-T1 


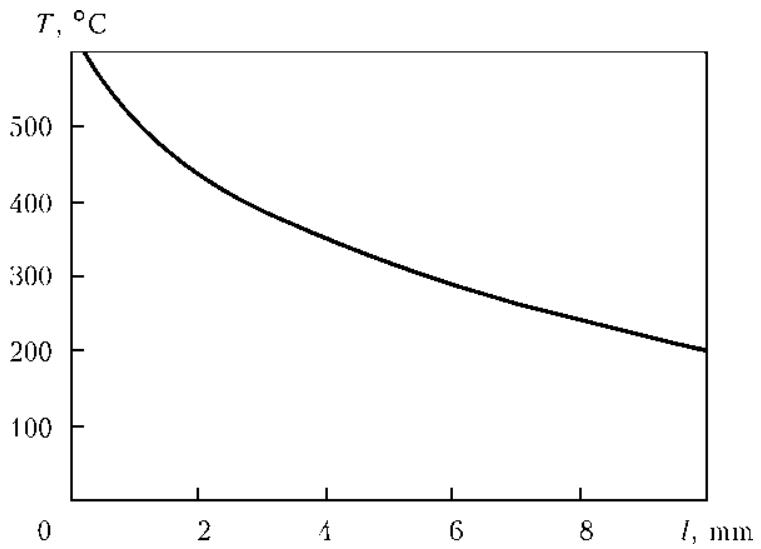

Figure 4. Distribution of temperature for depth $l$ heated by flashing of near-contact zone $4.0 \mathrm{~mm}$ thick plate of alloy D16-T before upsetting

V95-T1 with thickness of flanges $\delta=2.5$ and $4.0 \mathrm{~mm}$. Welding fixture in the form of jigs was designed for the experiments on welding.

Welding of specimens was carried out in the universal laboratory machine for FBW with continuous flashing, which was equipped by a pneumo-hydraulic drive of upsetting at the force $F_{\text {ups }}=130 \mathrm{kN}$ and welding transformer of $150 \mathrm{kV} \cdot \mathrm{A}$ capacity.

Differences in physical properties of alloys (heat conductivity of alloy AK6 is by $30 \%$ higher than that of alloy D16 [2, 3]) have a great influence on their heating during flashing, weld formation, character of deformation and structural transformations in the HAZ.

Selection and subsequent correction of welding modes were carried out experimentally with account for above-mentioned peculiarities of alloys. Express analysis of the welded joint quality, consisting in bending of notched specimens across weld up to fracture, was carried out in the process of run-out of the welding modes. The joint quality was evaluated by the presence or absence of defects in visual inspection of the specimen, fractured across weld (oxide films, etc.). Attempts were made to minimize the time of welding in welding modes to reduce the metal weakening
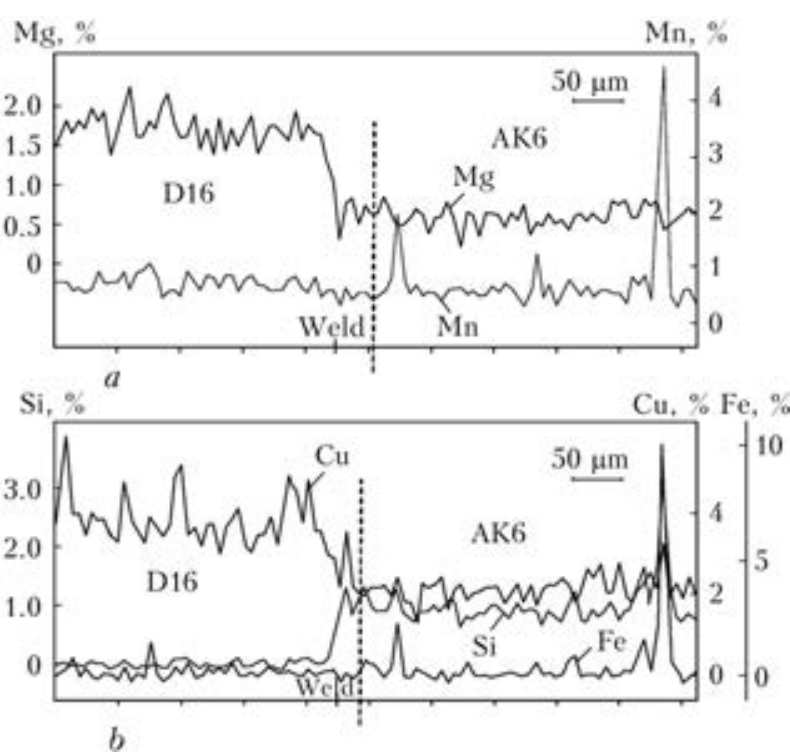

Figure 5. Distribution of elements in welded joint $(a)$ and HAZ (b)

during heating. Using the described procedure, the optimum modes, which provide the absence of defects in fusion line, were determined.

Main parameters of welding: secondary voltage $U_{20 . c}=4 \mathrm{~V}$, rate of flashing is changed exponentially from 2 up to $25 \mathrm{~mm} / \mathrm{s}$, upsetting rate is not more than $5 \mathrm{~s}$, time of welding is not more than $5 \mathrm{~s}$.

The distribution of temperature in near-contact zone of edges heated by flashing directly before upsetting is given in Figure 4.

To determine the redistribution of alloying elements between alloys in weld, the X-ray spectral microanalysis of AK6-T1 + D16-T welded joints was made (Figure 5). Transition zone of redistribution of alloying elements in weld is approximately $300 \mu \mathrm{m}$. Beyond the transition zone the content of alloying elements in weld corresponds to the base metal composition.

In the process of upsetting the texture of welded joint with a typical turning of base metal fibers at $90^{\circ}$ is formed as a result of extrusion of metal between the forming devices. Figure 6 gives

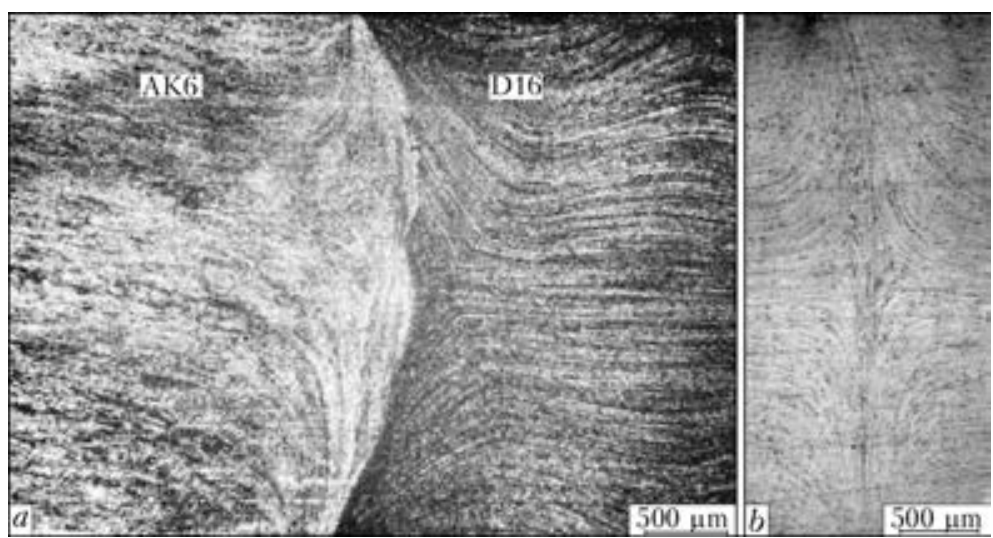

Figure 6. Macrostructure of welded joint butt: $a-$ AK6 + D16; $b-$ V95 


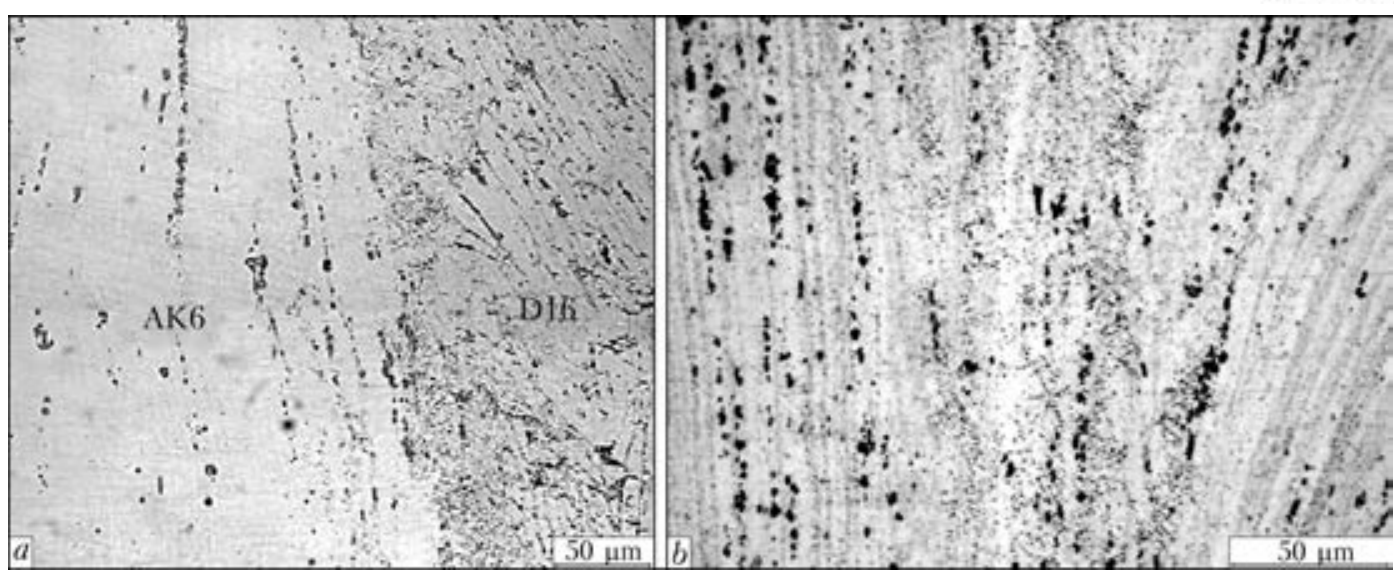

Figure 7. Microstructure of weld alloy AK6-T1 + D16-T $(a)$ and V95-T1 $(b)$ joints
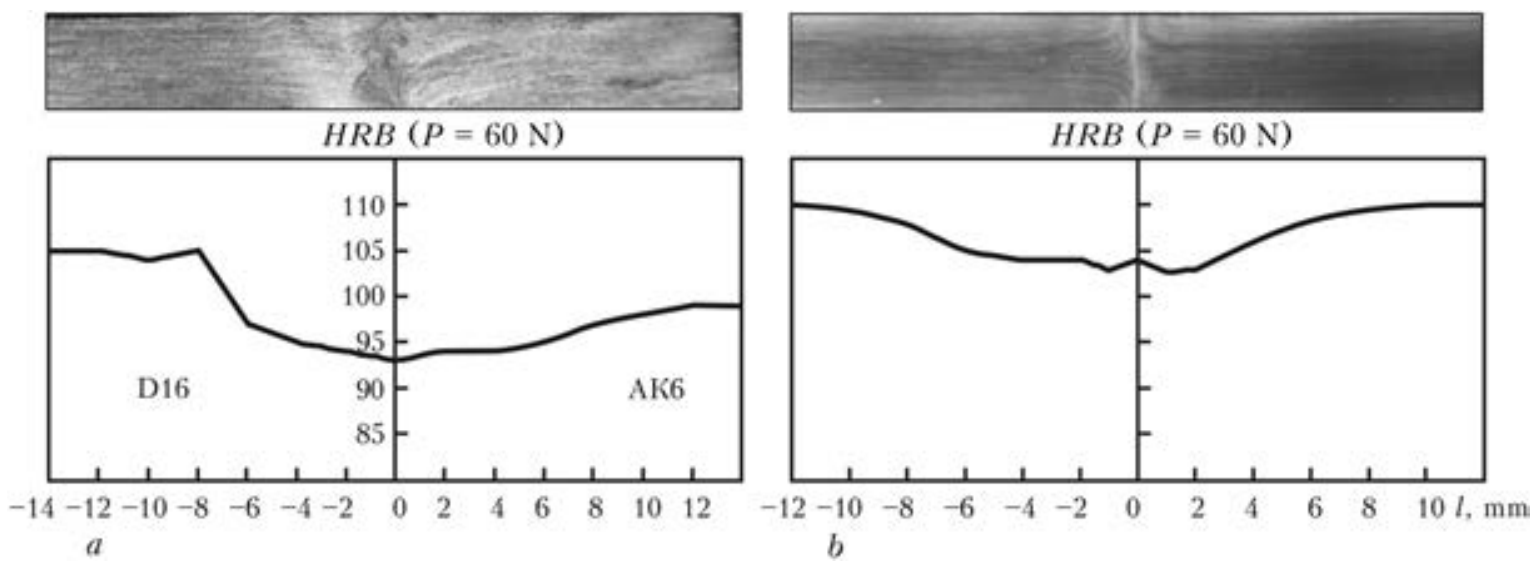

Figure 8. Distribution of hardness in welded joint of plates from alloys AK6-T1 + D16-T and profile of alloy V95-T1 (b)

the microstructures of welded joints. The microstructure of the joint zone is characterized by the deformed elongated grains of solid solution at a high density of intermetallic phases in the form of elongated chains (Figure 7). With weld approaching the intermetallic inclusions are refined. In the structure of welded joint profile of alloy V95-T1 the weld $6.0 \mu \mathrm{m}$ thick is formed, which has a typical fine-grained structure of solid solution and refined intermetallic phases of 1.0 $2.0 \mu \mathrm{m}$.

According to the results of carried out investigations of the distribution of metal hardness in welded joints (Figure 8) the total HAZ value is $15-20 \mathrm{~mm}$, maximum weakening of weld does not exceed $6 \%$.

Results of mechanical tests of the base metal and welded specimens of AK6-T1 + D16-T alloys showed the strength of the welded joints at the level of base metal of the less strong alloy AK6-T1 $\left(\sigma_{t}^{\mathrm{W}}=386 \mathrm{MPa}, \sigma_{\mathrm{t}}^{\mathrm{BM} \text { AK6 }}=387 \mathrm{MPa}, \sigma_{\mathrm{t}}^{\mathrm{BM} \text { D16 }}=\right.$ $=455 \mathrm{MPa})$. Specimens were fractured in HAZ on the side of alloy AK6-T1.

The strength of welded joints of V95-T1 alloy profile is at the level higher than $90 \%$ of the base metal strength $\left(\left(\sigma_{\mathrm{t}}^{\mathrm{w}}=521-542 \mathrm{MPa}\right.\right.$, $\left.\sigma_{\mathrm{t}}^{\mathrm{BM}} \mathrm{B} 95-\mathrm{T} 1=580 \mathrm{MPa}\right)$
From the obtained results of investigations the positive conclusion can be made about the challenging application of FBW technology with continuous flashing for joining the elements of thin-walled profiles of high-strength aluminium alloys in critical structures. This technology makes it possible to weld elements of structures in heat-hardened state with a loss in strength of not more than $10 \%$.

1. Nikolaev, G.A., Fridlyander, I.N., Arbuzov, Yu.P. (1990) Aluminium alloys to be welded. Moscow: Metallurgiya.

2. (1973) Aluminium alloys. Application of aluminium alloys: Manual. Ed. by A.T. Tumanov, I.N., Fridlyander. Moscow: Metallurgiya.

3. (1984) Commercial aluminium alloys: Refer. Book. Ed. by F.I. Kvasov, I.N. Fridlyander. Moscow: Metallurgiya.

4. Kuchuk-Yatsenko, S.I., Chvertko, P.N., Semyonov, L.A. et al. (2010) Peculiarities of flash butt welding of high-strength aluminium alloy 2219. The Paton Welding J., 3, 7-9.

5. Kuchuk-Yatsenko, S.I. (1992) Flash-butt welding. Kiev: Naukova Dumka.

6. Kuchuk-Yatsenko, S.I., Chvertko, P.N., Semyonov, L.A. et al. (2013) Flash butt welding of products of high-strength alloys based on aluminium. The Paton Welding J., 7, 2-6. 